\title{
IDENTIFIKASI FAKTOR PEMBENTUK PERILAKU PENCARI KERJA GENERASI Z DI INDONESIA
}

\section{IDENTIFICATION OF BEHAVIOR FACTORS OF GENERATION Z JOB SEEKERS IN INDONESIA}

\author{
Hanifah $^{* 1}$ dan Prabu Wardono*) \\ ${ }^{*}$ Fakultas Desain dan Seni Rupa, Institut Teknologi Bandung \\ Jln. Ganesha 10 Bandung 40132, Indonesia
}

\begin{abstract}
This study aims to identify the factors shaping the behavior of generation $Z$ job seekers in Indonesia. This research was conducted in generation Z (birth year 19952010) by involving 150 respondents divided into 50 student respondents each in the fields of technology, creative, and business, most of them lived in Jakarta and Bandung. The questionnaire was distributed online via google docs. This research uses quantitative methods. The form of a questionnaire outlined in online form via google docs with a total of 33 Likert scale question items. Confirmatory factor analysis (CFA) is used to determine the factors shaping the behavior of generation $Z$ job seekers in Indonesia. The results of this study indicate that the dimensions of intrinsic, extrinsic, altruistic, status, and social work values are able to measure the latent variables of generation $Z$ work behavior. In this study, it was found that the three dimensions that had the greatest contribution were the altruistic, status, and social work values. The social dimension is the same as the research findings in Turkey, while the altruistic and social dimensions are the same as the research findings in India. This study recommends that the concept of workspace needs to pay attention to the distance between employees because generation $Z$ wants a workplace where they want to have a good relationship with their colleagues and can help each other, when observed from the altruistic and social work value factors. There should also be a refuge room facility so that employees can focus more on completing their work which can increase their capacity, as indicated by to the status factor.
\end{abstract}

Keywords: workspace, work behavior, work value, generation $z$, confirmatory factor analysis

\begin{abstract}
Abstrak: Penelitian ini bertujuan mengidentifikasi faktor pembentuk perilaku para pencari kerja generasi $\mathrm{Z}$ di Indonesia. Penelitian ini dilakukan pada generasi Z (tahun kelahiran 1995-2010) dengan melibatkan 150 orang responden dengan pembagian 50 responden mahasiswa masing-masing pada bidang teknologi, kreatif, dan bidang bisnis yang sebagian besar berdomisili di Jakarta dan Bandung. Penyebaran kuesioner dilakukan secara online melalui google docs. Penelitian ini menggunakan metode kuantitatif. Alat ukur berupa kuesioner dituangkan dalam bentuk online melalui google docs dengan jumlah 33 item pertanyaan berskala Likert. Analisis faktor konfirmatori (CFA) digunakan untuk mengetahui faktor pembentuk perilaku para pencari kerja generasi $\mathrm{Z}$ di Indonesia. Hasil penelitian ini menunjukkan dimensi nilai kerja intrinsik, ekstrinsik, altruistik, status, dan sosial mampu mengukur variabel laten perilaku kerja generasi Z. Dalam penelitian ini ditemukan tiga dimensi yang memiliki kontribusi terbesar yaitu oleh nilai kerja altruistik, status, sosial. Untuk dimensi sosial sama dengan temuan penelitian di Turki, sedangkan untuk dimensi altruistik dan sosial sama dengan temuan penelitian di India. Penelitian ini merekomendasikan konsep ruang kerja yang perlu memperhatikan jarak antar karyawan karena generasi $\mathrm{Z}$ menginginkan tempat kerja dimana mereka ingin memiliki hubungan yang baik dengan rekan kerjanya serta dapat saling membantu, jika dilihat dari faktor nilai kerja altruistik dan sosial. Sebaiknya juga disediakan fasilitas ruang refuge (ruang perlindungan) supaya karyawan lebih fokus untuk menyelesaikan pekerjaannya yang dapat meningkatkan kapasitasnya, terkait dengan faktor status.
\end{abstract}

Kata kunci: ruang kerja, perilaku kerja, nilai kerja, generasi z, analisis faktor konfirmatori

\footnotetext{
${ }^{1}$ Alamat Korespondensi:

Email: hanihanifah@y7mail.com
} 


\section{PENDAHULUAN}

BPS-KPPPA (2018) mengatakan bahwa generasi Z lahir pada tahun 1995 sampai 2010. Jika Generasi $\mathrm{Z}$ pertama adalah mereka yang lahir pada tahun 1995, maka orang yang paling tua dari generasi ini sudah berusia 25 tahun pada tahun 2020. Generasi Z adalah generasi yang paling muda yang baru masuk angkatan kerja. Dalam penelitiannya Dwidienawati dan Gandasari (2018) mengatakan bahwa Generasi Z diperkirakan pada tahun 2020 Generasi Z akan mengusasai $20 \%$ dari tempat kerja, serta peristiwa dan perkembangan global akan berdampak pada berbagai negara dengan laju dan intensitas yang berbeda, oleh karena itu, karakteristik generasi ini akan berbeda dari khas budaya dan negara.

Beberapa penelitian menyebutkan bahwa perusahaan menghadapi masalah mengenai empat generasi saat ini aktif dipasar tenaga kerja sehingga dapat menimbulkan konflik antar generasi, karena memiliki nilai-nilai, ambisi, dan gaya kerja yang berbeda. Untuk mencegah terjadinya konflik antar generasi dalam ruang kerja, diperlukan desain ruang kerja yang tepat agar dapat membatasi dan mencegah perilaku yang tidak diinginkan. Krasner dan Ullmann (1973) dalam Hidjaz (2011) mengungkapkan bahwa lingkungan adalah faktor terpenting yang dapat membatasi kemungkinan perilaku yang mengartikan kemungkinan perilaku (potential behavior) dapat dibatasi oleh kondisi lingkungan. Menurut Hidjaz (2011) perilaku dengan suasana ruang memiliki sifat timbal balik yang dipengaruhi oleh faktor desain interior ruang. Printich (dalam, Amalia 2016) mengatakan bahwa yang mendasari individu dalam berperilaku berorientasi pada tujuan (goal oriented), dengan kata lain keputusan individu dalam berperilaku didukung oleh suatu keinginan untuk mencapai tujuan. Perilaku kerja karyawan di ruang kerja secara langsung maupun tidak langsung berkaitan dengan unsur-unsur 'sosiologis', 'psikologis' serta 'psikologi lingkungannya. Margaretha (2012) mengatakan bahwa, budaya yang dibawa oleh tiap karyawan mempengaruhi karyawan tersebut dalam berperilaku. Berdasarkan hal tersebut, maka memahami perilaku manusia adalah kunci utama dalam membentuk suatu organisasi. Dengan memahami perbedaan perilaku, seorang manajer dapat mengelolanya dan mengarahkan perilaku kerja yang positif demi mencapai tujuan secara efektif dan efisien. Hal tersebut merupakan tantangan besar, karena setiap karyawan mempunyai perbedaan karakteristik (Syafri, 2008 dalam Fabio et al. 2016).

Perkembangan generasi dari masa ke masa sangat menarik untuk diteliti, terutama untuk saat ini yakni generasi $Z$ yang mulai memasuki dunia kerja. Beberapa penelitian yang sebelumnya sudah pernah dilakukan menemukan terdapat lima faktor pembentuk perilaku kerja, faktor tersebut adalah faktor nilai kerja intrinsik, faktor nilai kerja ekstrinsik, faktor nilai kerja altruistik, faktor nilai kerja terkait status, dan faktor nilai kerja terkait sosial. Berdasarkan hal tersebut, maka perlu dilakukan analisis konfirmatori dari penelitian terdahulu yang akan disesuaikan dengan generasi $\mathrm{Z}$ yang ada di Indonesia. Perbedaan penelitian ini dengan penelitian terdahulu adalah penelitian ini dapat menghasilkan rekomendasi konsep ruang kerja yang sesuai bagi generasi $\mathrm{Z}$ di Indonesia khususnya pada bidang kreatif, teknologi, dan ekonomi bisnis.

Pendekatan penyelesaian masalah pada penelitian ini berkaca pada penelitian yang dilakukan Agarwal dan Vaghela pada tahun 2018 di India mengenai nilai kerja generasi $\mathrm{Z}$ dikarenakan faktor dan indikator perilaku kerja generasi $Z$ yang sudah mewakilii keseluruhan peneliti sebelumnya. Penelitian ini menjelaskan nilai kerja generasi $\mathrm{Z}$ yang berbeda dari generasi sebelumnya di India. Penelitian ini juga memberikan gambaran mengenai ekspektasi lingkungan kerja bagi generasi $\mathrm{Z}$ di India. Manfaat dari penelitian ini adalah untuk memberikan gambaran kepada peneliti selanjutnya supaya dapat mengkonfirmasi serta mengevaluasi beberapa variabel dan indikator yang dapat mempengaruhi perilaku kerja generasi $\mathrm{Z}$ yang akan disesuaikan di negara lainnya.

Karena preferensi pekerjaan dan tempat kerja berbeda untuk generasi yang berbeda, penting untuk memahami preferensi perilaku kerja generasi $\mathrm{Z}$ sehingga komunikasi yang tepat terbentuk dan lingkungan yang baik tercipta dalam suatu perusahaan. Penting untuk memahami apa yang memotivasi generasi $\mathrm{Z}$ untuk produktif sehingga menimbulkan suatu perilaku dalam perusahaan. Preferensi tempat kerja generasi $\mathrm{Z}$ berdasarkan literatur dan peneliti terdahulu adalah sebagai berikut: a) Berdasarkan penelitian Mustafa Ozkan, Betul Solmaz (2015), bahwa bagi generasi Z lingkungan sosial adalah faktor utama dalam memilih tempat kerja. Efek lingkungan sosial merupakan faktor penting untuk membentuk budaya organisasi 
ketika generasi $\mathrm{Z}$ masuk dalam organisasi. Jika mereka tidak dapat menemukan kebahagiaan ini di tempat mereka bekerja, mereka akan berpikir untuk berhenti dari pekerjaan dengan mudah; b) Maria (2016) mengungkapkan dalam penelitiannya bahwa generasi $\mathrm{Z}$ berharap untuk dibimbing oleh atasannya dan keinginan untuk mengembangkan hubungan kerja yang baik. Generasi $\mathrm{Z}$ tidak ingin bekerja secara terpisah, tetapi cenderung lebih suka bekerja dalam kelompok, di kantor ruang terbuka; c) Dalam penelitian Sandhya dan Ritu (2017) mengungkapkan bahwa secara intrinsik generasi $\mathrm{Z}$ termotivasi. menyediakan tempat kerja yang menyenangkan akan memastikan kesetiaan dan kinerja mereka untuk perusahaan; d) Dalam penelitian Arthur (2018) mengungkapkan bahwa generasi $\mathrm{Z}$ mencari tempat kerja dimana mereka ingin tumbuh dan berkembang dalam pekerjaannya; e) Diena Dwidienawati dan Dyah Gandasari (2018) mengatakan bahwa generasi $\mathrm{Z}$ di Indonesia realistis dan membutuhkan keamanan dan stabilitas. Uang adalah motivasi penting; oleh karena itu, mereka bersedia bekerja keras dan dipindahkan untuk kesempatan kerja yang layak. Mereka lebih suka komunikasi tatap muka dengan atasan mereka. Mereka juga warga global yang bertanggung jawab secara social; f) Agarwal dan Pratiksinh (2018) mengungkapkan dalam penelitiannya, bahwa bagi generasi $\mathrm{Z}$ nilai kerja Intrinsik, nilai kerja Altruistik, dan Status adalah nilai yang penting dalam memilih tempat kerja, baik bagi laki-laki maupun perempuan. Pada nilai kerja altruistik, responden cenderung ingin saling berbagi pengetahuan serta mengharapkan lingkungan kerja yang dapat saling membantu. Pada nilai kerja ekstrinsik, responden cenderung ingin bergabung dengan perusahaanperusahaan yang akan memberi mereka kesempatan untuk tumbuh di dalam perusahaan, sehingga mereka dapat memiliki karir yang panjang, dan menghargai manfaat dari karir. Dibandingkan dengan Milenial, generasi $\mathrm{Z}$ terdengar kurang matrealistis. Mereka ingin memiliki keseimbangan kehidupan kerja bersama dengan lingkungan yang menyenangkan. Bagi generasi $Z$, hubungan yang baik dengan rekan kerja mereka adalah hal yang penting. Penelitian ini juga menemukan bahwa motivasi generasi $\mathrm{Z}$ adalah lingkungan kerja yang baik.

Dengan pertimbangan beberapa penelitian sebelumnya, ruang lingkup dalam penelitian ini adalah generasi $\mathrm{Z}$ yang saat ini memasuki jenjang mahasiswa yang mempelajari bidang teknologi, kreatif dan bisnis karena banyak riset yang mengatakan, bahwa generasi $\mathrm{Z}$ ahli di bidang teknologi, memiliki kreatifitas yang tinggi, dan berjiwa wirausaha. Penelitian ini bertujuan untuk mengkonfirmasi perilaku pencari kerja generasi $\mathrm{Z}$ di Indonesia dengan perilaku pencari kerja generasi $\mathrm{Z}$ dinegara lainnya yang faktor pembentuknya sudah ditemukan oleh peneliti sebelumnya. Selain itu, penelitian juga bertujuan untuk mengetahui faktor yang paling berkontribusi besar dalam membentuk variabel laten perilaku kerja generasi $\mathrm{Z}$ dan indikator yang memiliki kontribusi besar pada masing-masing faktor.

Hasil dari penelitian diharapkan dapat memberikan gambaran kedepannya pada perusahaan mengenai karakteristik perilaku kerja generasi $\mathrm{Z}$ di Indonesia khususnya di bidang kreatif, teknologi, dan bisnis, serta cara menghadapi generasi $\mathrm{Z}$ di dunia kerja. Dari hasil analisis juga dapat dijadikan rekomendasi konsep ruang kerja bagi generasi $\mathrm{Z}$ terutama pada bidang kreatif, teknologi, dan ekonomi bisnis.

\section{METODE PENELITIAN}

Penyebaran kuesioner dilakukan secara online melalui google docs pada tanggal 13 Maret hingga 24 Maret 2020. Populasi penelitian ini adalah masyarakat Indonesia yang termasuk dalam generasi $\mathrm{Z}$ (tahun kelahiran 1995-2010). Subjek yang diteliti merupakan generasi $\mathrm{Z}$ yang kini sudah pada jenjang mahasiswa, karena pada jenjang mahasiswa generasi $\mathrm{Z}$ sedang mempersiapkan diri untuk memasuki dunia kerja.

Pada penelitian ini dibutuhkan dua jenis data, yakni data sekunder dan data primer. Data sekunder diperoleh dari penelitian terdahulu, jurnal, dan literatur yang terkait dengan perilaku kerja generasi $\mathrm{Z}$ serta karakteristik generasi Z. Penulis merujuk pada penelitian yang sudah dilakukan oleh Agarwal dan Vaghela (2018) dan didukung oleh penelitian terdahulu lainnya. Data primer didapatkan melalui kuesioner yang sudah disusun dan dirancang sesuai dengan teori dan data sekunder yang sudah diperoleh sebelumnya terkait perilaku kerja generasi Z. Kuesioner merujuk pada penelitian yang sudah dilakukan oleh Agarwal dan Vaghela (2018) dan penulis kembangkan kembali berdasarkan teori-teori yang sudah dikemukakan oleh peneliti sebelumnya. Kuesioner yang sudah dirancang diuji coba terlebih dahulu kepada 25 responden yang disebar secara online. Pada tahap uji coba, kuesioner diuji reliabilitas model 
pengukurannya. Setelah itu kuesioner disebar dan data responden ini akan diolah dan dianalisa menggunakan statistik Confirmatory Factor Analysis (CFA), dengan bantuan perangkat lunak Lisrel versi 8.8.

Pemilihan sampel menggunakan teknik Purposive Sampling karena mahasiswa yang dijadikan responden adalah mahasiswa yang berada di bidang teknologi, desain, dan ekonomi bisnis, sehingga diluar bidang tersebut tidak diteliti. Dikarenakan jumlah populasi generasi $\mathrm{Z}$ di Indonesia tidak terhingga, sehingga penentuan jumlah sampel menggunakan metode Bernaoulli (Sedarmayanti, 2011):

$$
\mathrm{N}=\frac{\left(Z_{\alpha / 2}\right)^{2} \cdot \sigma^{2}}{\mathrm{e}^{2}}
$$

Keterangan: N (jumlah sampel minimum); Z (nilai distribusi normal $(1,96)$ ); $\alpha$ (tingkat signifikansi $(0,95)$ ); e (tingkat kesalahan 10\% $(0,1))$; $\sigma$ (simpangan baku (simpangan baku maksimum 0,5$)$ ).

Berikut adalah hasil dari perhitungan jumlah sampel minimum:

$$
\begin{aligned}
& \mathrm{N}=\frac{(1,96)^{2}}{0,1^{2}} \\
& \mathrm{~N}=96,04
\end{aligned}
$$

Berdasarkan hasil tersebut, maka jumlah sampel minimum yang diperlukan sebesar 96 responden. Riadi (2018) mengatakan bahwa penelitian dengan teknik Structural Equation Modeling (SEM) membutuhkan jumlah sampel minimal sebesar 150 responden. Maka penyebaran kuesioner dibatasi dengan melibatkan 150 orang responden dengan pembagian 50 responden berasal dari mahasiswa bidang teknologi, 50 responden dari mahasiswa bidang desain, dan 50 responden dari mahasiswa bidang bisnis.

Karena di negara lain terutama sudah banyak penelitian serupa dilakukan, maka penelitian ini menerapkan metodologi kuantitatif dengan pendekatan analisis faktor konfirmatori. Metode ini dilakukan dengan asumsi bahwa faktor pembentuk perilaku pekerja di kalangan generasi $\mathrm{Z}$ telah ditemukan di negara lain, namun belum terkonfirmasi di Indonesia. Penelitian ini menggunakan metode second order CFA, dimana pada metode ini terdiri dari dua tingkat. Pada tingkat pertama (first order confirmatory) analisis faktor konfirmatori menunjukan hubungan antara indikator-indikator pengukur dari lima variabel laten pembentuk perilaku kerja generasi $Z$, yaitu faktor nilai kerja intrinsik, faktor nilai kerja ekstrinsik, faktor nilai kerja altruistik, faktor nilai kerja terkait status, dan faktor nilai kerja terkait sosial. Setelah masing-masing hubungan indikatorindikator dengan variabel pembentuk perilaku kerja diketahui, kemudian masuk pada tingkat kedua. Tingkat kedua (second order confirmatory) analisis faktor konfirmatori menunjukan hubungan antara variabelvariabel laten pembentuk perilaku kerja generasi $\mathrm{Z}$ dari sebuah variabel laten perilaku kerja generasi $Z$.

\section{Variabel penelitian dan alat ukur}

Kuesioner penelitian bersumber dari penelitian sebelumnya (Agarwal dan Vaghela, 2018) dikarenakan variabel dan indikator sudah mewakili dari keseluruhan temuan peneliti sebelumnya. Dari kuesioner tersebut kemudian penulis kembangkan lagi indikator lain untuk mengukur variabel. Penjelasan operasionalisasi dari variable dan indikator penelitian yang digunakan pada Tabel 1.

\section{Hipotesis Penelitian}

Peneliti akan menguji konstruk perilaku kerja yang sudah ditemukan oleh peneliti sebelumnya. Menurut Ye (2015) nilai-nilai kerja adalah tujuan dari apa yang dikejar individu dalam pekerjaan mereka dan itu adalah pengaruh langsung pada pilihan dan kemampuan individu. Berdasarkan hal tersebut, dalam memilih pekerjaan, seorang individu memiliki pendapat sebelumnya yang sudah terbentuk tentang apa yang seharusnya dan tidak seharusnya terjadi. Kemudian timbul perilaku dan hasil-hasil tertentu yang ingin dilakukannya. Twenge (2010) mengungkapkan bahwa untuk menarik generasi baru sebagai karyawan secara efektif, sebuah perusahaan harus memahami nilai kerja mereka. Menurut Agarwal dan Vaghela (2018) bahwa, terdapat lima nilai kerja yang dapat mempengaruhi perilaku kerja generasi Z, yakni faktor nilai kerja intrinsik, faktor nilai kerja ekstrinsik, faktor nilai kerja altruistik, faktor nilai kerja terkait status, dan faktor nilai kerja terkait sosial. Berdasarkan penjelasan tersebut, maka hipotesis penelitian yang diajukan adalah nilai kerja intrinsik, ekstrinsik, altruistik, status, dan sosial sebagai pembentuk perilaku pencari kerja generasi $\mathrm{Z}$ terbukti secara empirik di Indonesia. 
Tabel 1. Operasionalisasi indikator dari variabel penelitian

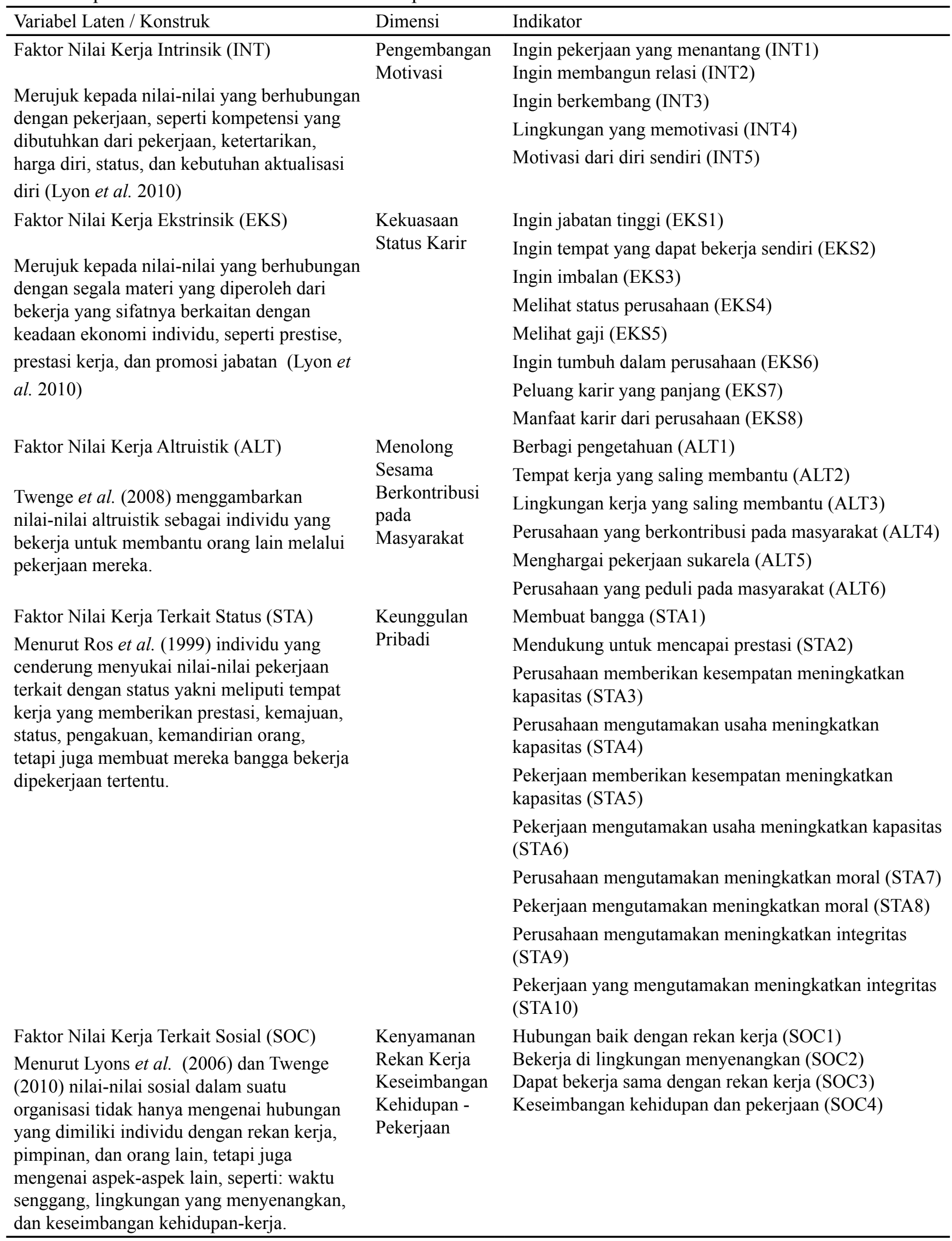


Jumlah item pertanyaan pada penelitian ini terdapat 33 butir pertanyaan. Kuesioner ditujukan untuk mengetahui respon perilaku generasi Z ketika mereka akan melamar pekerjaan dengan susunan pilihan jawaban yang terdiri dari 5 poin skala Likert. Jawaban poin 5 adalah yang paling positif terletak dibagian paling kanan dan jawaban poin 1 adalah paling negatif terletak di bagian kiri.

\section{Hubungan Variabel}

Variabel dalam penelitian ini adalah perilaku kerja generasi $\mathrm{Z}$ (PK) yang dibentuk dari lima faktor variabel laten, yakni faktor nilai kerja intrinsik (INT), faktor nilai kerja ekstrinsik (EKS), faktor nilai kerja altruistik (ALT), faktor nilai kerja terkait status (STA), dan faktor nilai kerja terkait sosial (SOC). Gambar 1 berikut menjelaskan skema hubungan antar variabel.

\section{Hasil Pengujian Reliabilitas Model Pengkuran}

Kuesioner yang sudah dirancang diuji coba terlebih dahulu kepada 25 responden yang disebar secara online. Pada tahap uji coba, kuesioner diuji reliabilitas model pengukurannya. Uji reliabilitas ini difokuskan pada masing-masing variabel pembentuk perilaku kerja generasi Z. Berikut adalah hasil uji reliabilitas yang diolah dengan program SPSS dapat dilihat pada Tabel 2.

Berdasarkan hasil tersebut, keseluruhan variabel pembentuk perilaku kerja dengan total item pertanyaan sebanyak 33 item memiliki nilai Cronbach's Alpha lebih dari 0,7. Hasil tersebut menunjukan seluruh variabel yang diuji tersebut sudah menunjukkan reliabilitas yang konsisten. Sehingga dapat disimpulkan bahwa semua konstruk variabel pembentuk perilaku kerja adalah reliabel dan layak digunakan dalam proses pengambilan data.

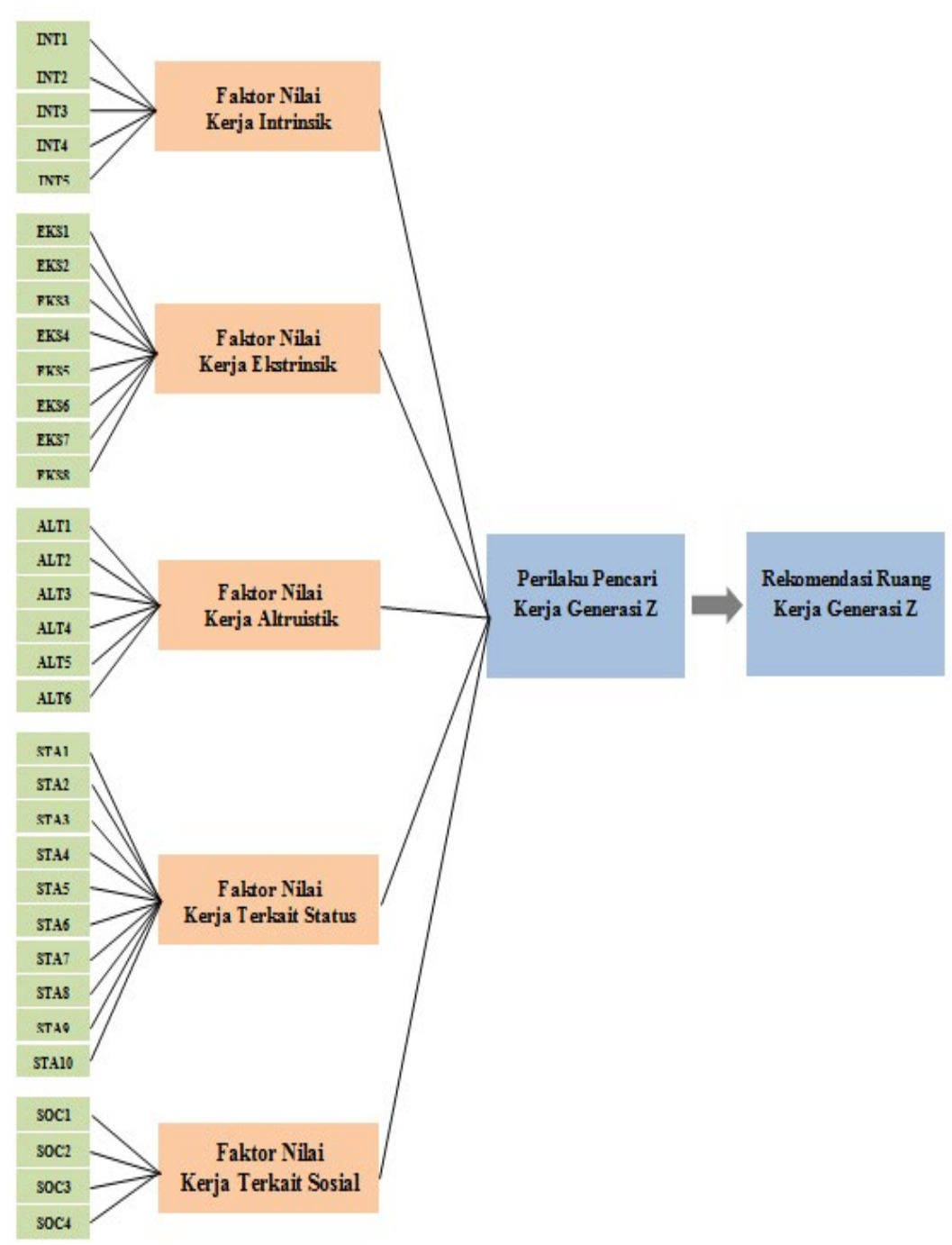

Gambar 1. Penjelasan arah berfikir hubungan variabel 
HASIL

\section{Karakteristik Responden}

Berdasarkan Tabel 3, diketahui responden pada penelitian ini didominasi oleh jenis kelamin perempuan sebanyak 79 orang (52,7\%). Responden yang merupakan generasi $\mathrm{Z}$ pada jenjang mahasiswa didominasi oleh mereka yang lahir pada tahun 1999 saat ini menginjak usia 21 tahun sebanyak 28 orang $(18,7 \%)$. Responden didominasi oleh mahasiswa yang berasal dari ITB sebanyak 47 orang $(31,3 \%)$. Universitas lain-lain ini diantaranya terdapat dari universitas Binus, universitas Multimedia Nusantara, universitas Maranatha, dan sebagainya.

\section{Analisis First Order CFA pada Variabel Laten Pembentuk Perilaku Kerja}

Berdasarkan Tabel 4, hasil menunjukan bahwa terdapat beberapa indikator yang tidak valid. Hal ini ditunjukan dari nilai faktor loading yang kurang dari taraf signifikan $(\leq 0,50)$, sehingga indikator tersebut harus dihilangkan karena tidak memberikan kontribusi yang baik dan valid dalam pengukuran dimensi variabel laten atau konstruk. Pada tabel 5 menunjukan hasil analisis setelah indikator yang tidak valid sudah dihilangkan dan sudah dihitung nilai construct reliability pada masing-masing variabel laten:

Tabel 2. Pengujian reliabilitas model pengukuran

\begin{tabular}{lcc}
\hline Konstruk & Alpha Cronbach's & Keterangan \\
\hline Nilai kerja intrinsik & 0,7 & Reliabel \\
Nilai kerja ekstrinsik & 0,79 & Reliabel \\
Nilai kerja altruistik & 0,77 & Reliabel \\
Nilai kerja terkait status & 0,87 & Reliabel \\
Nilai kerja terkait sosial & 0,81 & Reliabel \\
\hline
\end{tabular}

Tabel 3. Karakteristik responden

\begin{tabular}{|c|c|c|}
\hline \multicolumn{2}{|c|}{ Karakteristik Responden } & \multirow{2}{*}{$\frac{\text { Jumlah }(\mathrm{N}) \text { dan Presentase }(\%)}{71 \text { orang }(47,3 \%)}$} \\
\hline Jenis Kelamin & Laki-Laki & \\
\hline & Perempuan & 79 orang $(52,7 \%)$ \\
\hline \multirow[t]{7}{*}{ Usia } & 25 tahun & 21 orang $(14 \%)$ \\
\hline & 24 tahun & 26 orang $(17,3 \%)$ \\
\hline & 23 tahun & 23 orang $(15,3 \%)$ \\
\hline & 22 tahun & 17 orang $(11,3 \%)$ \\
\hline & 21 tahun & 28 orang $(18,7 \%)$ \\
\hline & 20 tahun & 16 orang $(10,7 \%)$ \\
\hline & $<20$ tahun & 19 orang $(12,8 \%)$ \\
\hline \multirow[t]{6}{*}{ Universitas Asal } & ITB & 47 orang $(31,3 \%)$ \\
\hline & Mercu Buana & 28 orang $(18,7 \%)$ \\
\hline & Universitas Brawijaya & 18 orang $(12 \%)$ \\
\hline & President University & 9 orang $(6 \%)$ \\
\hline & Universitas Gunadarma & 13 orang $(8,7 \%)$ \\
\hline & Lain-lain & 35 orang $(23,3 \%)$ \\
\hline
\end{tabular}


Tabel 4. Nilai faktor loading indikator terhadap konstruk pembentuk perilaku kerja generasi Z

\begin{tabular}{|c|c|c|c|}
\hline Variabel Laten / Konstruk & Indikator & Nilai Faktor Loading & Keterangan \\
\hline \multirow{5}{*}{$\begin{array}{l}\text { Faktor Nilai Kerja Intrinsik } \\
\text { (INT) }\end{array}$} & INT1 & 0,12 & Tidak Valid \\
\hline & INT2 & 0,22 & Tidak Valid \\
\hline & INT3 & 0,44 & Tidak Valid \\
\hline & INT4 & 0,82 & Valid \\
\hline & INT5 & 0,65 & Valid \\
\hline \multirow{8}{*}{$\begin{array}{l}\text { Faktor Nilai Kerja Ekstrinsik } \\
\text { (EKS) }\end{array}$} & EKS1 & 0,17 & Tidak Valid \\
\hline & EKS2 & 0,17 & Tidak Valid \\
\hline & EKS3 & 0,29 & Tidak Valid \\
\hline & EKS4 & 0,46 & Tidak Valid \\
\hline & EKS5 & 0,33 & Tidak Valid \\
\hline & EKS6 & 0,70 & Valid \\
\hline & EKS7 & 0,44 & Tidak Valid \\
\hline & EKS8 & 0,72 & Valid \\
\hline \multirow{6}{*}{$\begin{array}{l}\text { Faktor Nilai Kerja Altruistik } \\
\text { (ALT) }\end{array}$} & ALT1 & 0,67 & Valid \\
\hline & ALT2 & 0,73 & Valid \\
\hline & ALT3 & 0,67 & Valid \\
\hline & ALT4 & 0,59 & Valid \\
\hline & ALT5 & 0,58 & Valid \\
\hline & ALT6 & 0,71 & Valid \\
\hline \multirow{10}{*}{$\begin{array}{l}\text { Faktor Nilai Kerja Terkait } \\
\text { Status (STA) }\end{array}$} & STA1 & 0,34 & Tidak Valid \\
\hline & STA2 & 0,63 & Valid \\
\hline & STA3 & 0,80 & Valid \\
\hline & STA4 & 0,83 & Valid \\
\hline & STA5 & 0,84 & Valid \\
\hline & STA6 & 0,84 & Valid \\
\hline & STA7 & 0,61 & Valid \\
\hline & STA8 & 0,64 & Valid \\
\hline & STA9 & 0,78 & Valid \\
\hline & STA10 & 0,80 & Valid \\
\hline \multirow{4}{*}{$\begin{array}{l}\text { Faktor Nilai Kerja Terkait } \\
\text { Sosial (SOC) }\end{array}$} & SOC1 & 0,78 & Valid \\
\hline & SOC2 & 0,73 & Valid \\
\hline & SOC3 & 0,61 & Valid \\
\hline & SOC4 & 0,48 & Tidak Valid \\
\hline
\end{tabular}

Berdasarkan hasil Tabel 5, indikator yang memiliki nilai faktor loading lebih dari 0,5 sudah mewakili persepsi responden terhadap konstruk atau variabel laten pembentuk perilaku kerja, sehingga item dinyatakan valid dan memberikan konstribusi yang baik, serta mampu mengukur variabel laten. Berdasarkan hasil analisis diatas, maka pada variabel laten nilai kerja intrinsik persepsi responden cenderung pada indikator ke-4, yakni generasi $\mathrm{Z}$ menginginkan lingkungan kerja yang memotivasi dengan nilai faktor loading sebesar 0,98 . Pada variabel laten nilai kerja ekstrinsik persepsi responden cenderung pada indikator ke-6, yakni generasi $\mathrm{Z}$ ingin tumbuh dalam perusahaan dengan nilai faktor loading sebesar 1 . Pada variabel laten nilai kerja altruistik persepsi responden cenderung pada indikator ke-2, yakni mereka menginginkan tempat kerja dimana generasi $\mathrm{Z}$ dapat saling membantu dengan rekan kerjanya dengan nilai loading faktor sebesar 0,73. Pada variabel laten nilai kerja terkait status persepsi responden cenderung pada indikator ke-5, yakni generasi $\mathrm{Z}$ menginginkan pekerjaan yang dapat meningkatkan kapasitas untuk menyelesaikan tugasnya dengan nilai loading faktor sebesar 0,9. Dan pada variabel laten nilai kerja terkait sosial persepsi responden cenderung pada indikator ke-1, yakni generasi $\mathrm{Z}$ menginginkan hubungan yang baik dengan rekan kerjanya dengan nilai loading faktor sebesar 0,82 . 
Tabel 5. Nilai construct reliability pada konstruk pembentuk perilaku kerja generasi Z

\begin{tabular}{|c|c|c|c|c|}
\hline Variabel Laten / Konstruk & Indikator & Nilai Faktor Loading & Nilai Error Variance & Construct Reliability (CR) \\
\hline \multirow{2}{*}{$\begin{array}{l}\text { Faktor Nilai Kerja Intrinsik } \\
\text { (INT) }\end{array}$} & INT4 & 0,98 & 0,05 & \multirow[t]{2}{*}{0,76} \\
\hline & INT5 & 0,56 & 0,68 & \\
\hline \multirow{2}{*}{$\begin{array}{l}\text { Faktor Nilai Kerja Ekstrinsik } \\
\text { (EKS) }\end{array}$} & EKS6 & 1,00 & 0 & \multirow[t]{2}{*}{0,79} \\
\hline & EKS8 & 0,58 & 0,66 & \\
\hline \multirow{6}{*}{$\begin{array}{l}\text { Faktor Nilai Kerja Altruistik } \\
\text { (ALT) }\end{array}$} & ALT1 & 0,67 & 0,56 & \multirow[t]{6}{*}{0,82} \\
\hline & ALT2 & 0,73 & 0,47 & \\
\hline & ALT3 & 0,67 & 0,54 & \\
\hline & ALT4 & 0,59 & 0,65 & \\
\hline & ALT5 & 0,58 & 0,67 & \\
\hline & ALT6 & 0,71 & 0,49 & \\
\hline \multirow{9}{*}{$\begin{array}{l}\text { Faktor Nilai Kerja Terkait } \\
\text { Status (STA) }\end{array}$} & STA2 & 0,58 & 0,66 & \multirow[t]{9}{*}{0,90} \\
\hline & STA3 & 0,82 & 0,33 & \\
\hline & STA4 & 0,87 & 0,24 & \\
\hline & STA5 & 0,9 & 0,19 & \\
\hline & STA6 & 0,87 & 0,25 & \\
\hline & STA7 & 0,51 & 0,74 & \\
\hline & STA8 & 0,53 & 0,72 & \\
\hline & STA9 & 0,67 & 0,55 & \\
\hline & STA10 & 0,68 & 0,53 & \\
\hline \multirow{3}{*}{$\begin{array}{l}\text { Faktor Nilai Kerja Terkait } \\
\text { Sosial (SOC) }\end{array}$} & SOC1 & 0,82 & 0,33 & \multirow[t]{3}{*}{0,75} \\
\hline & $\mathrm{SOC} 2$ & 0,72 & 0,48 & \\
\hline & $\mathrm{SOC} 3$ & 0,59 & 0,66 & \\
\hline
\end{tabular}

Hasil perhitungan nilai construct reliability first order CFA pada masing-masing konstruk atau variabel laten pembentuk perilaku generasi $\mathrm{Z}$ sudah memenuhi kriteria karena memiliki nilai CR lebih dari 0,70. Hasil tersebut mengindikasikan bahwa tingkat reliabilitas pada konstruk adalah cukup tinggi. Sehingga dapat disimpulkan bahwa indikator-indikator pada tiap konstruk mendukung model untuk variabel laten pembentuk perilaku pencari kerja generasi $\mathrm{Z}$.

\section{Analisis Second Order CFA pada Variabel Laten Perilaku Kerja}

Sebelumnya sudah dilakukan pengujian first order CFA pada masing-masing variabel laten pembentuk perilaku kerja untuk mendapatkan model second order CFA pada variabel laten perilaku kerja. Sehingga didapatkan hasil yang optimum pada model dengan indikator yang telah memenuhi kriteria valid dan reliabel. Gambar 2 berikut menunjukan konstruk variabel perilaku pencari kerja generasi $\mathrm{Z}$

Berdasarkan Tabel 6, diketahui kelima variabel laten pembentuk perilaku kerja signifikan membentuk variabel laten perilaku kerja, yakni nilai kerja intrinsik (INT), nilai kerja ekstrinsik (EKS), nilai kerja altruistik (ALT), nilai kerja terkait status (STA), nilai kerja terkait sosial (SOC). Hal ini ditunjukan dari nilai faktor loading yang lebih dari taraf signifikan $(\geq 0,50)$, sehingga dapat disimpulkan bahwa pada kelima item variabel laten pembentuk perilaku kerja memberikan kontribusi yang baik dan valid dalam mengukur variabel laten perilaku kerja (PK). Berdasarkan hal tersebut maka hipotesis penelitian dapat diterima. Nilai faktor loading terbesar terdapat pada nilai kerja altruistik, yakni sebesar 0,67. Hal ini menunjukan bahwa nilai kerja altruistik memiliki pengaruh terbesar terhadap perilaku kerja generasi $\mathrm{Z}$ di Indonesia. Begitu juga dengan nilai kerja terkait status dan nilai kerja terkait sosial.

Nilai construct reliability second order CFA perilaku kerja (PK) menghasilkan nilai sebesar 0,74 nilai tersebut sudah memenuhi kriteria karena lebih dari 0,7 . Hasil tersebut mengindikasikan bahwa tingkat reliabilitas pada konstruk adalah cukup tinggi. Sehingga dapat dikatakan bahwa data mendukung model untuk variabel laten perilaku kerja generasi $\mathrm{Z}$. 


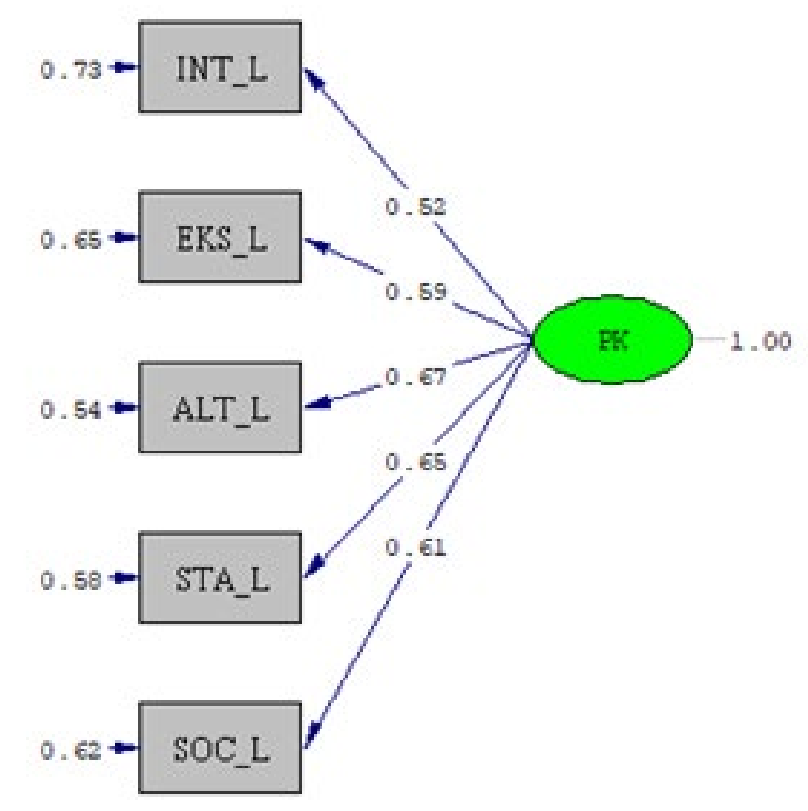

Chi-Square $=0.04, d f=5, p-v a l u e=0.99998$, RMSEA $=0.000$

Gambar 2. Path diagram variabel perilaku kerja

Tabel 6. Nilai faktor loading dan nilai construct reliability pada konstruk perilaku kerja generasi Z

\begin{tabular}{lllll}
\hline & Variabel Laten / Konstruk & $\begin{array}{l}\text { Nilai Faktor } \\
\text { Loading }\end{array}$ & $\begin{array}{l}\text { Nilai Error } \\
\text { Variance }\end{array}$ & $\begin{array}{l}\text { Construct } \\
\text { Reliability }\end{array}$ \\
\hline Perilaku Kerja & Faktor Nilai Kerja Intrinsik (INT) & 0,52 & 0,73 & 0,74 \\
Generasi Z (PK) & Faktor Nilai Kerja Ekstrinsik (EKS) & 0,59 & 0,65 & \\
& Faktor Nilai Kerja Altruistik (ALT) & 0,67 & 0,54 & \\
& Faktor Nilai Kerja Terkait Status (STA) & 0,65 & 0,58 & \\
& Faktor Nilai Kerja Terkait Sosial (SOC) & 0,61 & 0,62 & \\
\hline
\end{tabular}

Identifikasi model berdasarkan derajat kebebasan (degree of freedom) didapatkan model dengan $d f=5$. Hal tersebut menunjukan model masuk dalam kategori over-identified. Tabel 7 berikut hasil pengolahan data oleh program Lisrel versi 8.8 pada uji kriteria Goodness of Fit (GOF)

Dapat dilihat bahwa secara keseluruhan dari kelima konstruk atau variabel laten pembentuk perilaku kerja kriteria kebaikan model telah terpenuhi. Hal tersebut dilihat karena masing-masing indikator memiliki nilai melebihi batas ambangnya dan sudah memenuhi kriteria fit. Sehingga dapat dikatakan bahwa model dapat diterima.

Hasil analisis menunjukan bahwa hubungan keseluruhan dari kelima variabel laten pembentuk perilaku kerja memiliki nilai loading faktor lebih dari 0,5 , sehingga hipotesis penelitian dapat diterima. Dapat disimpulkan bahwa kelima faktor nilai kerja tersebut berkontribusi dalam membentuk variabel laten perilaku kerja generasi Z. Maka diketahui bahwa faktor pembentuk perilaku kerja generasi $Z$ yang sudah ditemukan di negara lain oleh peneliti sebelumnya, sama dengan di Indonesia. Hasil pada penelitian ini mengkonfirmasi bahwa faktor nilai kerja altruistik $(0,67)$, nilai kerja terkait status $(0,65)$, dan nilai kerja terkait sosial $(0,61)$ memberikan kontribusi terbesar terhadap variabel laten perilaku kerja generasi $\mathrm{Z}$ di Indonesia. Berbeda dengan hasil temuan penelitian Agarwal dan Vaghela tahun 2018 yang menunjukan bahwa kontribusi terbesar terdapat pada nilai kerja intrinsik, nilai kerja altruistik, dan nilai kerja terkait status. Begitu juga dengan hasil penelitian Ozkan dan Solmaz tahun 2015 yang menunjukan bahwa hanya faktor nilai kerja terkait sosial yang paling penting bagi generasi Z. Berdasarkan hasil pada temuan ini, maka teori yang sudah dikemukakan oleh Tsang dan Chiu pada tahun 2000 (dalam Amar, 2011) mengenai indikator penting yang dapat mempengaruhi perilaku 
kerja, salah satunya yaitu social behavior (hubungan sosial) dapat dipertahankan sebagai penentu perilaku kerja generasi $\mathrm{Z}$ di Indonesia. Begitu juga dengan teori yang dikemukakan oleh Bryson pada tahun 1997 (dalam Amar, 2011) mengenai indikator yang dapat mempengaruhi perilaku kerja yaitu, CooperativenessSocial Skill (Kemampuan Berhubungan Sosial) dan Work Motivation (motivasi kerja) dapat dipertahankan sebagai penentu perilaku kerja generasi $\mathrm{Z}$ di Indonesia.

Berdasarkan hasil analisis data, terdapat dua indikator yang mampu menjelaskan dimensi faktor nilai kerja intrinsik yaitu indikator ke-4 dan indikator ke-5, dimana persepsi responden cenderung pada indikator ke-4, yakni mereka menginginkan lingkungan kerja yang memotivasi dengan nilai loading faktor sebesar 0,98 . Temuan ini serupa dengan hasil penelitian Agarwal dan Vaghela (2018) bahwa pada faktor nilai kerja intrinsik, responden cenderung ingin memiliki lingkungan kerja yang dapat memotivasi mereka. Berdasarkan hal tersebut, maka dimensi "motivasi" dan "pengembangan diri” yang terdapat pada faktor nilai kerja intrinsik dapat dipertahankan sebagai indikator dalam mengukur perilaku kerja generasi Z di Indonesia.

Pada faktor nilai kerja ekstrinsik terdapat dua indikator yang mampu menjelaskan dimensi tersebut yaitu indikator ke-6 dan indikator ke-8, dimana persepsi responden cenderung pada indikator ke-6 yakni mereka ingin tumbuh dalam perusahaan dengan nilai loading faktor sebesar 1. Temuan tersebut serupa dengan hasil penelitian Arthur M. Baldonado (2018) serta Agarwal dan Vaghela (2018) bahwa generasi Z ingin mencari tempat kerja dimana mereka ingin diberi kesempatan untuk tumbuh dan berkembang dalam pekerjaan mereka. Pada penelitian ini indikator ke-8 juga mampu menjelaskan faktor nilai kerja ekstrinsik, yaitu manfaat karir dari perusahaan. Temuan tersebut juga serupa dengan penelitian Agarwal dan Vaghela bahwa generasi $\mathrm{Z}$ menghargai manfaat dari karir mereka. Temuan ini selaras dengan pernyataan Jaskyte (2014) yang mengatakan bahwa individu dapat memilih tempat kerja tertentu berdasarkan tempat kerja yang memberikan manfaat bagi individu. Selain itu, temuan dari hasil penelitian ini mengkonfirmasi bahwa generasi $\mathrm{Z}$ di Indonesia tidak melihat pekerjaan dari gaji, hal tersebut ditunjukan dengan indikator ke-5 yang memiliki nilai faktor loading sebanyak 0,33 , dimana indikator tersebut tidak memiliki kontribusi yang baik dan tidak valid dalam membentuk nilai kerja ekstrinsik. Temuan tersebut serupa dengan temuan Agarwal dan Vaghela (2018) bahwa generasi Z terdengar kurang matrealistis, ditunjukan dengan indikator ke-5 yaitu generasi $\mathrm{Z}$ memilih pekerjaan melihat dari gaji yang memiliki nilai faktor loading kurang dari 0,5 yakni sebesar 0,33. Namun hal ini bertentangan dengan temuan Dwidienawati dan Gandasari (2018), bahwa generasi $\mathrm{Z}$ di Indonesia termotivasi dengan uang. Begitu juga bertentangan dengan pernyataan Stillman dan Stillman (2017) yang mengatakan bahwa sebagian besar generasi $\mathrm{Z}$ menempatkan gaji pada urutan teratas. Berdasarkan hasil temuan penelitian ini dan penjelasan di atas maka dimensi "karir" yang terdapat pada faktor nilai kerja ekstrinsik dapat dipertahankan sebagai indikator dalam mengukur perilaku kerja generasi $\mathrm{Z}$ di Indonesia. Sedangkan pada dimensi "kekuasaan" dan "status" pada faktor nilai kerja ekstrinsik tidak dapat dipertahankan sebagai indikator dalam mengukur perilaku kerja generasi $\mathrm{Z}$ di Indonesia, karena jika dilihat dari hasil analisis di atas generasi $Z$ di Indonesia tidak menjadikan jabatan dan uang sebagai motivasi utama.

Tabel 7. Tabel Goodness of fit variabel perilaku kerja.

\begin{tabular}{lccr}
\hline Indikator GOF & Kriteria 'Fit' & Hasil Model & Keterangan \\
\hline Chi Square & Diharapkan kecil & 0.04 & - \\
\hline P-value & $\mathrm{P} \geq 0,05$ & 0,99 & Baik \\
NFI & $\geq 0,9$ & 1,00 & Sangat Baik \\
CFI & $\geq 0,9$ & 1,00 & Sangat Baik \\
RFI & $\geq 0,9$ & 1,00 & Sangat Baik \\
GFI & $\geq 0,9$ & 0,97 & Baik \\
RMSEA & $\leq 0,08$ & 0,00 & Sangat Baik \\
AGFI & $\geq 0,9$ & 0,90 & Baik \\
\hline
\end{tabular}


Seluruh indikator pada variabel laten nilai kerja altruistik mampu menjelaskan dimensi nilai kerja altruistik. Berdasarkan temuan tersebut dapat diketahui bahwa generasi $\mathrm{Z}$ di Indonesia tidak memprioritaskan diri sendiri melainkan untuk kebaikan orang lain. Generasi Z lebih mementingkan orang lain terlebih dahulu daripada dirinya sendiri tanpa mengharapkan imbalan. Persepsi responden cenderung pada indikator ke-2, yakni mereka menginginkan tempat kerja dimana mereka dapat saling membantu dengan rekan kerjanya dengan nilai loading faktor sebesar 0,73. Temuan tersebut serupa dengan hasil penelitian Maria Christina (2016) serta Agarwal dan Vaghela (2018) bahwa generasi $\mathrm{Z}$ tidak ingin bekerja secara terpisah, tetapi mereka lebih suka bekerja dalam kelompok sehingga mereka dapat saling membantu. Berdasarkan hal tersebut, maka dimensi "menolong sesama" dan "berkontribusi pada masyarakat" yang terdapat pada faktor nilai kerja altruistik dapat dipertahankan sebagai indikator dalam mengukur perilaku kerja generasi $\mathrm{Z}$ di Indonesia.

Pada faktor nilai kerja terkait status terdapat sembilan indikator yang mampu mengukur dimensi nilai kerja ini yaitu indikator ke-2 hingga indikator ke-10, dimana persepsi responden cenderung pada indikator ke-5, yakni mereka menginginkan pekerjaan yang dapat meningkatkan kapasitas untuk menyelesaikan tugasnya dengan nilai loading faktor sebesar 0,9 . Hasil penelitian tersebut sejalan dengan hasil temuan Fabio et al. (2016) bahwa, karyawan merasa bangga ketika mereka menyelesaikan pekerjaannya yang memiliki pengaruh terbesar terhadap faktor motivasi kerja. Dari hasil temuan tersebut dapat diketahui bahwa generasi $\mathrm{Z}$ di Indonesia cenderung menyukai nilai perkerjaan terkait dengan status. Seperti yang sudah dijelaskan sebelumnya oleh Ros et al. pada tahun 1999 (dalam Agarwal dan Vaghela, 2018), berarti generasi Z di Indonesia suka membandingkan diri mereka dengan orang lain dan tujuannya adalah mencapai keunggulan pribadi. Berdasarkan hal tersebut, maka dimensi "keunggulan pribadi" yang terdapat pada faktor nilai kerja terkait status dapat dipertahankan sebagai indikator dalam mengukur perilaku kerja generasi $\mathrm{Z}$ di Indonesia.

Dan pada faktor nilai kerja terkait sosial terdapat tiga indikator yang dapat mengukur nilai kerja ini yaitu indikator ke-1 hingga indikator ke-3, dimana persepsi responden cenderung pada indikator ke-1, yakni mereka menginginkan hubungan yang baik dengan rekan kerjanya dengan nilai loading faktor sebesar 0,82 . Temuan tersebut serupa dengan hasil penelitian Maria Christina (2016) serta Agarwal dan Vaghela (2018) yang menunjukan bahwa generasi $\mathrm{Z}$ ingin mengembangkan hubungan kerja yang baik. Pada generasi ini sudah memanfaatkan teknologi untuk berkomunikasi jarak jauh dan akses internet sudah menjadi kebutuhan bagi generasi $\mathrm{Z}$, sehingga pada generasi ini lebih banyak berhubungan sosial melalui dunia maya agar mereka tetap terhubung. Dalam bukunya, Stillman dan Stillman (2017) mengatakan bahwa $84 \%$ dari generasi $Z$ menyukai komunikasi tatap muka dengan atasan dan $78 \%$ generasi $Z$ lebih menyukai komunikasi tatap muka dengan rekan sebaya. Sehingga sampai saat ini berkomunikasi dengan tatap muka langsung di lingkungan kerja masih utama dilakukan meskipun di era saat ini manusia dapat berkomunikasi melalui sosial media. Karena terdapat hal-hal terbatas yang tidak mungkin dibuat suatu aplikasi, dan koneksi manusia adalah salah satunya. Penelitian ini juga mengkonfirmasi bahwa indikator ke-2 "bekerja di lingkungan menyenangkan" dan indikator ke-3 "dapat bekerja sama dengan rekan kerja" memiliki kontribusi yang baik dalam membentuk nilai kerja terkait sosial, hal ini dapat dilihat pada nilai faktor loading yang memiliki nilai $\leq 0,5$. Berdasarkan hasil tersebut, maka dimensi "kenyamanan" dan "rekan kerja" yang terdapat pada faktor nilai kerja terkait sosial dapat dipertahankan sebagai indikator dalam mengukur perilaku kerja generasi $\mathrm{Z}$ di Indonesia. Sedangkan pada dimensi "keseimbangan kehidupan-pekerjaan" pada faktor nilai kerja terkait sosial tidak dapat dipertahankan sebagai indikator dalam mengukur perilaku kerja generasi $\mathrm{Z}$ di Indonesia.

\section{Implikasi Manajerial}

Implikasi manajerial dibuat berdasarkan hasil penelitian yang menunjukan adanya kontribusi besar pada nilai kerja altruistik, nilai kerja terkait status, dan nilai kerja terkait sosial terhadap perilaku kerja generasi $\mathrm{Z}$ di bidang kreatif, teknologi, serta bisnis. Cara yang dilakukan adalah dengan mengadakan acara kebersamaan yang dapat meningkatkan kolaborasi seperti makan siang bersama, liburan bersama, acara gathering diluar kantor, dan sebagainya. Menurut Ernanto dkk (2015, dalam Julianry et al. 2017) bahwa, salah satu indikator yang mempunyai kontribusi terbesar terhadap budaya perusahaan adalah teamwork. Hasil kerja akan lebih optimal apabila para karyawan memiliki kemauan untuk bekerja secara tim untuk 
menyelesaikan pekerjaannya dengan tujuan yang sama (Fitlya, 2016). Dukungan dari karyawan yang merupakan investasi perusahaan tersebut berasal dari kinerja karyawannya (Margaretha, 2012). Maka dari itu penting bagi perusahaan untuk meningkatkan rasa kebersamaan antar karyawan karyawan demi menciptakan kinerja bermutu yang dapat dijadikan sebagai investasi manusia bagi masa depan perusahaan dengan cara meningkatkan kolaborasi serta kerja sama tim.

Cara lainnya yaitu perusahaan dapat menyediakan tempat kerja dimana karyawan generasi $\mathrm{Z}$ dapat saling membantu dengan rekan kerjanya, sehingga konsep ruang kerja perlu memperhatikan jarak antar karyawan karena generasi $\mathrm{Z}$ menginginkan tempat kerja dimana mereka ingin memiliki hubungan yang baik dengan rekan kerjanya, membuat mereka ingin selalu dekat. Konsep terbuka pada ruang kerja dirasa cocok bagi generasi $\mathrm{Z}$ khususnya dibidang kreatif, teknologi, serta bisnis agar rekan kerja dapat dengan mudah berkomunikasi sehingga dapat meningkatkan sosialisasi antar pegawai. Quible dalam Badri (2007) mengatakan, bahwa jaringan komunikasi merupakan salah satu faktor yang perlu diperhatikan dalam perencanaan tata ruang dan konsep ruang kerja supaya lebih efektif dan efisien. Desain ruang terbuka juga merepresentasikan bahwa generasi $\mathrm{Z}$ merupakan generasi yang memiliki sifat terbuka (Andrea et al. 2016). Menurut Sedarmayanti (2011), bahwa tata ruang kantor terbuka merupakan ruang kerja yang cukup luas ditempati oleh beberapa pegawai untuk bekerja bersama di ruang termaksud tanpa dipisah oleh penyekat/pembatas yang permanen. Hal ini sejalan dengan temuan Maria Christina (2016) bahwa generasi $\mathrm{Z}$ senang bekerja di ruang terbuka sehingga mereka dapat bekerja bersama-sama dengan temannya. Sebaiknya juga disediakan fasilitas ruang refuge (ruang perlindungan) supaya karyawan lebih fokus untuk menyelesaikan pekerjaannya yang dapat meningkatkan kapasitasnya ketika mereka merasa bising, terkait dengan faktor status. Selain itu disediakannya fasilitas ruang yang dapat mendukung kerja tim dan meningkatkan kolaborasi, seperti ruang meeting komunal, café, dan sebagainya. Baldonado (2018) mengatakan bahwa, lingkungan kerja yang menyenangkan baik fisik maupun sosial, serta nyaman dapat memotivasi kelompok generasi Z. Setiawan (2014) mengatakan, bahwa menata warna di tempat kerja perlu dirancang sebaik-baiknya karena dapat memainkan peran penting untuk menciptakan suasana ruang serta memiliki pengaruh terhadap perasaan.
Fitria (2018) mengatakan, bahwa wana kuning cocok diterapkan pada ruang kerja karena memiliki pengaruh untuk meningkatkan konsentrasi. Dengan lingkungan fisik yang dapat memfasilitasi generasi $\mathrm{Z}$ dalam meningkatkan sosialisasi dan memiliki lingkungan yang menyenangkan, generasi $\mathrm{Z}$ dapat tinggal lebih lama di tempat kerjanya. Hasil analisis ini tidak dapat digeneralisasikan pada keseluruhan generasi $\mathrm{Z}$ di Indonesia karena responden pada penelitian ini sebagian besar berasal dari Jakarta dan Bandung.

\section{KESIMPULAN DAN SARAN}

\section{Kesimpulan}

Penelitian ini menemukan bahwa dimensi nilai kerja intrinsik, nilai kerja ekstrinsik, nilai kerja altruistik, nilai kerja terkait status, dan nilai kerja terkait sosial mampu mengukur variabel laten perilaku kerja generasi Z. Maka dapat dikonfirmasi bahwa faktor pembentuk perilaku kerja generasi $Z$ di Indonesia sama dengan yang ada pada generasi $\mathrm{Z}$ di negara lainnya dari temuan peneliti sebelumnya. Hasil pada penelitian ini mengkonfirmasi bahwa nilai kerja altruistik, nilai kerja terkait status, dan nilai kerja terkait sosial memberikan kontribusi besar terhadap variabel laten perilaku kerja generasi $\mathrm{Z}$ di Indonesia khususnya di Jakarta dan Bandung pada generasi $\mathrm{Z}$ di bidang kreatif, teknologi, serta bisnis. Hasil analisis ini tidak dapat digeneralisasikan pada keseluruhan generasi $\mathrm{Z}$ di Indonesia karena responden pada penelitian ini sebagian besar berasal dari Jakarta dan Bandung. Pada masing-masing variabel nilai kerja terdapat indikator yang memiliki kontribusi terbesar, yaitu pada nilai kerja intrinsik kontribusi terbesar diberikan oleh indikator ke-4 (ingin lingkungan kerja yang memotivasi); pada nilai kerja ekstrinsik kontribusi terbesar diberikan oleh indikator ke-6 (ingin tumbuh dalam perusahaan); pada nilai kerja altruistik kontribusi terbesar diberikan oleh indikator ke-2 (tempat kerja yang saling membantu); pada nilai kerja terkait status kontribusi terbesar diberikan oleh indikator ke-5 (pekerjaan memberikan kesempatan meningkatkan kapasitas); dan pada nilai kerja terkait sosial kontribusi terbesar diberikan oleh indikator ke-1 (hubungan baik dengan rekan kerja).

Dari hasil analisis yang sudah ditemukan maka dapat dicarikan rekomendasi konsep desain secara teknis. Rekomendasi desain ini dicarikan pada sumber lain yang paling mendekati dari hasil analisis pada 
penelitian. Desain pada ruang kerja menggunakan konsep terbuka, agar generasi $\mathrm{Z}$ mudah berkomunikasi dan bertukar ide baik dengan rekan kerja maupun dengan pemimpinnya khususnya di bidang kreatif, teknologi, serta bisnis karena tidak terdapat penyekat yang permanen. Agar pegawai generasi $\mathrm{Z}$ dapat lebih produktif serta dapat meningkatkan kolaborasi dan kerja sama tim, diperlukan fasilitas yang dapat digunakan secara bersama seperti ruang meeting baik komunal ataupun formal, café, dan sebagainya serta memanfaatkan pencahayaan alami agar ruang kerja terasa lebih hangat sehingga dapat menimbulkan rasa kedekatan antar rekan kerja. Fasilitas ruang refuge (ruang perlindungan) juga perlu diperhatikan untuk meningkatkan produktivitas kerja agar pegawai mencapai keunggulan pribadinya dalam menyelesaikan pekerjaan. Selain itu tersedianya fasilitas listrik dan internet yang siap akses dengan mudah oleh pegawai baik di meja kerja ataupun fasilitas penunjang.

\section{Saran}

Bagi perusahaan harus siap untuk menghadapi pekerja generasi $\mathrm{Z}$ yang saat ini sudah mulai memasuki dunia kerja dan penting untuk memahami perilaku pekerjanya karena itu adalah kunci utama dalam membentuk suatu organisasi. Dengan memahami perbedaan perilaku, seorang manajer dapat mengelolanya dan mengarahkan perilaku kerja yang positif demi mencapai tujuan secara efektif dan efisien. Variabel nilai kerja altruistik memiliki kontribusi terbesar terhadap perilaku kerja generasi Z. Oleh karena itu, hal ini sangat penting untuk mendapatkan perhatian yang besar dari perusahaan dan dapat ditingkatkan lagi dengan mengadakan acara serta fasilitas ruang kerja yang mendukung generasi $\mathrm{Z}$ agar dapat meningkatkan kolaborasi dan kerja sama tim. Bagi peneliti sendiri yang berprofesi sebagai desainer interior, dalam perancangan konsep ruang kerja perlu memperhatikan perilaku pengguna ruang sehingga ruang kerja sesuai dengan kebutuhan pengguna, bukan hanya mengikuti tren saja. Kelemahan pada penelitian ini adalah Sebagian besar responden berasal dari kota seperti Jakarta dan Bandung. Penelitian lebih lanjut dapat dilakukan mengenai perbedaan persepsi generasi $\mathrm{Z}$ di kota dan generasi $\mathrm{Z}$ yang ada di desa, yang akan mengkonfirmasi bahwa budaya dan perkembangan teknologi yang berbeda dapat mempengaruhi persepsi dan karakteristik generasi Z.

\section{DAFTAR PUSTAKA}

Agarwal H, Vaghela PS. 2018. Work Value of Gen Z. National Conference on Innovative Business Management Practices in 21st Century; India, 21-22 Des 2018. India: Faculty of Management Studies. hlm 1-26.

Amalia N. 2016. Hubungan Goal Orientation dan Motivasi Berprestasi dengan Intensi menyontek pada Mahasiswa Program Studi Psikologi Universitas Mulawarman. eJournal Psikologi 4(3): 295-306

Amar H. 2011. Pengaruh Kompetensi dan Perilaku Kerja Terhadap Kinerja Pemeriksa di Inspektorat Kabupaten Bangka [tesis]. Pangkalpinang: Program Pascasarjana, Universitas Terbuka.

Andrea B et al. 2016. Y and Z Generations at Workplaces. Journal of Competitiveness 8(3): 90-106.

Baldonado AM. 2018. Leadership and Gen Z: Motivating Gen $\mathrm{Z}$ Workers and Their Impact to the Future. International Journal of Managerial Studies amd Research 6(1): 56-60.

Badri MS. 2007. Manajemen Administrasi Perkantoran Modern. Jakarta : Erlangga

[BPS-KPPPA] Badan Pusat Statistik, Kementerian Pemberdayaan Perempuan dan Perlindungan Anak. 2018. Profil Generasi Milenial Indonesia. Jakarta: Kementerian Pemberdayaan Perempuan dan Perlindungan Anak.

Christina M. 2016. Generation Z and Its Perception of Work. Cross-Cultural Management Journal XVIII(1): 47-54.

Dwidienawati D, Gandasari D. 2018. Understanding Indonesia's Generation Z. International Journal of Engineering dan Technology 7(3.25): 245252.

Fabio BP, Hubeis M, Puspitawati H. 2016. Pengaruh Gaya Kepemimpinan, Motivasi Kerja Terhadap Komitmen Organisasi yang Berimplikasi pada Kinerja Karyawan. Jurnal Aplikasi Bisnis dan Manajemen 2(1): 91-104

Fitlya R. 2016. Peran Nilai Kerja Empat Faktor dan Kepemimpinan dengan Kontrak Psikologis Sebagai Mediator Terhadap Tim Kerja Efektif. Humanitas 13(1): 62-71

Fitria TA. 2018. Pengaruh Seting Ruang Terhadap Perilaku Pengguna Dengan Pendekatan Behavioral Mapping. Jurnal Arsitektur dan Perencanaan 1(2): 183-206.

Hidjaz T. 2011. Interaksi Perilaku Kerja dan Suasana 
Ruang di Perkantoran Kasus di 2 lokasi Kantor Pusat PT Telkom Bandung. Jurnal Itenas Rekarupa 1(1): 13-27.

Jaskyte K. 2014. Individual and Work Values of Nonprofit, Public, and Business Employees: How Similar or Different Are They?. Human Service Organizations: Management, Leadership dan Governance 38(3): 283-296.

Jualianry A, Syarief R, Affandi MK. 2017. Pengaruh

Pelatihan dan Motivasi Terhadap Kinerja Karyawan Serta Kinerja Organisasi Kementrian Komunikasi dan Informatika. Jurnal Aplikasi Bisnis dan Manajemen 3(2): 236-245

Margaretha M. 2012. Pengaruh Sikap Kerja Terhadap Kinerja Karyawan pada PT Duta Marga Silima In Jakarta. Jurnal Manajemen dan Bisnis 2(2): 151-166

Ozkan M, Solmaz B. 2015. The Changing Face of the Employees - Generation Z and Their Perceptions of Work (A Study Applied to University Students). Procedia Economics and Finance 26:
$476-483$.

Riadi E. 2018. Statistik SEM Structural Equation Modeling dengan LISREL. Yogyakarta: CV. Andi Offset.

Sedarmayanti. 2011. Tata Kerja dan Produktivitas Kerja. Bandung: CV Mandar Maju

Setiawan HB. 2014. Arsitektur, Lingkungan, dan Perilaku. Yogyakarta: Gadjah Mada University Press.

Stillman D, Stillman J. 2017. Generasi Z (Memahami Karakter Generasi Baru yang Akan Mengubah Dunia Kerja). Jusuf L, Alih Bahasa. Jakarta: PT Gramedia Pustaka Utama.

Tewari S, Bhattacharyya R. 2017. Aspirations dan Wants of Generation Z - A Study on the Work Force of the Future. Journal of Business and Economics 8(7): 607-614.

Twenge JM. 2010. A Review of the Empirical Evidence on Generational Differences in Work Attitudes. Journal of Business and Psychology 25(2): 201210

Ye L. 2015. Work values and career adaptability of Chinese University students. Social behaviour and personality: An international journal 43(3): 411-422. 